\title{
Triple pylorus
}

A 73-year-old woman was investigated for epigastric pain. Her medical history included coronary heart disease, which was being treated with aspirin $100 \mathrm{mg}$ once daily. Esophagogastroduodenoscopy revealed severe inflammation of the antrum and prepyloric region. There was pronounced edema of the pylorus, partially occluding the passage into the duodenal bulb and descending part of the duodenum, both of which showed normal mucosa. No peptic ulcer was identified and biopsy specimens were negative for Helicobacter pylori. A double contrast study of the stomach demonstrated a filiform pyloric stenosis and a single orifice with no gastroduodenal fistula ( Fig. 1). Endosonography with sampling for histological examination was carried out to exclude malignancy, and acid suppression therapy was started. A follow-up endoscopy after 3 months showed resolution of the mucosal inflammation. Inspection of the pyloric region now revealed a triple pylorus ( Fig.2). All three orifices were lined by normal gastroduodenal mucosa and allowed free passage into the duodenum ( Video 1 ). The patient was asymptomatic and reported no signs of delayed gastric emptying. Antacid therapy with proton pump inhibitors was continued and 1 year later, the patient is doing well. Triple pylorus is extremely rare $[1,2]$ and, similar to double pylorus, usually represents a gastroduodenal fistula resulting from penetrating ulcer disease, although congenital pyloric duplication may occur [3]. In our patient, the triple pylorus had most likely developed following peptic disease due to long-term aspirin use. Most fistulas persist after treatment with antacid medication, and there is no need for further endoscopic or surgical treatment in the absence of gastric outlet obstruction.

Endoscopy_UCTN_Code_CCL_1AB_2AD_3AF

Competing interests: None

Video 1

Gastric endoscopy revealing triple pylorus. All three orifices led to the duodenal bulb. After antacid therapy, the inflammation resolved completely, showing normal mucosa.

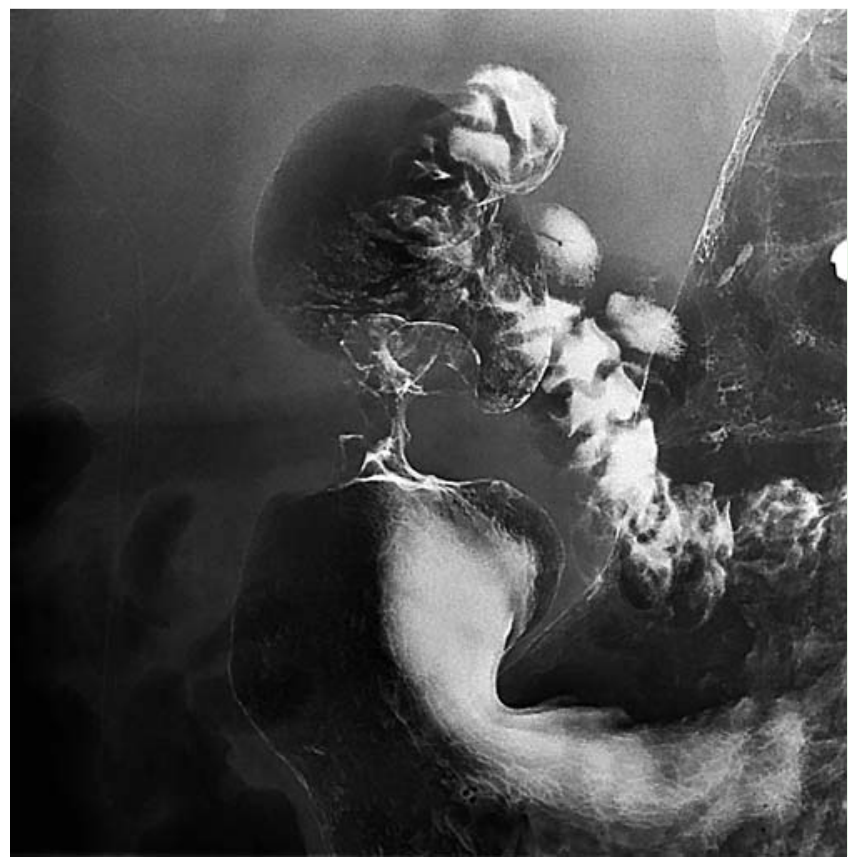

Fig. 1 Barium double contrast showing the gastroduodenal region with evident pyloric stenosis in a 73-year-old woman with epigastric pain and taking aspirin $100 \mathrm{mg}$ daily for coronary heart disease. No gastroduodenal fistulas are seen.

\section{E. Burri ${ }^{1}$, D. Toia ${ }^{2}$, R. Meier ${ }^{1}$}

${ }^{1}$ Department of Gastroenterology, Hepatology and Clinical Nutrition, Cantonal Hospital, Liestal, Switzerland

2 Department of Radiology, Cantonal Hospital, Liestal, Switzerland

\section{References}

1 Moses FM, Peura DA, Johnson LF. Triple lumen pylorus - a complication of peptic ulcer. Gastrointest Endosc 1985; 31: 23-25

2 Sansone N, Schnall HA, Somnay K. Evolution of the pylorus from a double to a triple lumen. Gastrointest Endosc 2009; 69: 949; discussion 950

3 Sufian S, Ominsky S, Matsumoto T. Congenital double pylorus. A case report and review of the literature. Gastroenterology 1977; 73 : 154-157

Bibliography

DOI http://dx.doi.org/

10.1055/s-0032-1310070

Endoscopy 2012; 44: E362

(c) Georg Thieme Verlag KG

Stuttgart · New York

ISSN 0013-726X

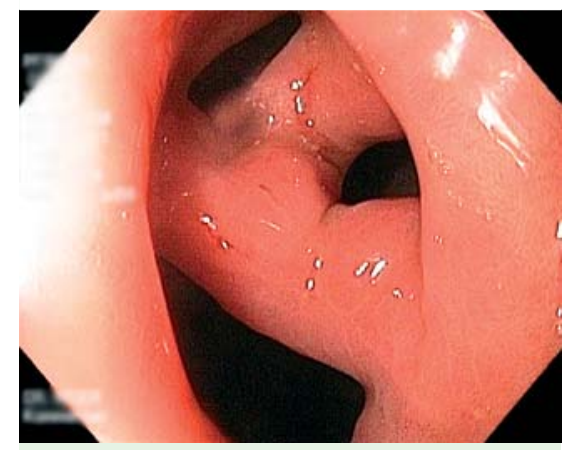

Fig.2 Gastric endoscopy of the pyloric region: the pylorus shows three orifices, all lined by normal mucosa.

Corresponding author

\section{Professor R. Meie}

Department of Gastroenterology,

Hepatology and Clinical Nutrition

University Hospital Liestal

Rheinstrasse 26

4410 Liestal

Switzerland

Fax: +41-61-9252813

remy.meier@ksli.ch 